\title{
Sensitivity Analysis of a Vertical Geothermal Heat Pump System
}

\author{
Chanjuan $\operatorname{Han}^{1}$, Xiong (Bill) $\mathrm{Yu}^{2 *}$ \\ ${ }^{1}$ Ph.D. Candidate, Department of Civil Engineering, Case Western Reserve University, 2104 Adelbert Road, \\ Bingham Building-Room 203B, Cleveland, OH 44106, cxh432@case.edu. \\ $2^{2 *}$ Associate Professor, Department of Civil Engineering, Department of Electrical Engineering and Computer \\ Science (courtesy appointment), Department of Mechanical and Aerospace Engineering (Courtesy Appointment), \\ Case Western Reserve University, 2104 Adelbert Road, Bingham Building-Room 206, Cleveland, OH 44106, \\ xxy21@case.edu, Corresponding author.
}

\begin{abstract}
This paper conducts sensitivity analyses on factors affecting the performance of vertical geothermal heat pump system, aiming to formulate design and operation strategies to improve its performance. It firstly describes the development of a 3D coupled Finite Element Model (FEM), which is utilized to simulate the steady state and transient behaviors of geothermal heat exchanger (GHE). The model holistically couples the heat exchange processes between pipe fluid flow, grouting backfill material, and adjacent ground associated with GHE. The model is firstly validated by comparison with the experimental data from an in-service GHE. Base on the calibrated model, a series of sensitivity analyses are conducted on the influence of geological, design, and operational factors intermittent operation mode of GHE achieves higher such as the initial ground temperature profile, GHE pipe installation depth, circulation fluid flow velocity, inlet temperature, subsurface water flow velocity, and material thermal properties. It also assess the behaviors of GHE under continuous operation versus intermittent operation modes. The results show that both design parameter (i.e., GHE pipe installation depth) and operational parameters (i.e, circulation fluid flow velocity) have major influence on the GHE performance. For a certain design length of GHE, the GHE performance improves with higher circulation fluid flow velocity until beyond a critical velocity. For GHE working in the heating mode, the heat extraction by GHE increases with decreasing fluid temperature at the inlet. In the geological factor aspect, the thermal conductivity of the ground material plays a very important role on the GHE performance operating in the continuous operation mode, while its specific heat capacity exerts no appreciable influence. However, for intermittent operation mode, both thermal conductivity and specific heat capacity of the ground, particularly the grouting materials, affect the ground thermal energy extraction. The results also showed that the presence of subsurface ground water flow improves the heat exchange of GHE. Operation wise, the GHE achieves higher performance and Coefficient of Performance (COP) under intermittent operation mode than under continuous operation mode. These observations point to ways to improve the performance of GHE from both design and operation aspects.
\end{abstract}

\section{Key words}

Geothermal; Ground Coupled Heat Pump (GCHP); coupled PDE; FEM; Sensitivity analysis; Optimization 
Over the past decades, the depletion of fossil energy along with the demand to reduce carbon footprint in the energy sector has promoted the development of renewable energy techniques including solar, wind, geothermal energy, bioenergy, hydropower, etc. The renewable energy revolution has spread worldwide, which accounted for $19 \%$ of the global energy generation in 2012 and quickly increased to 23\% in 2013 [1]. In the United States, the cumulative installation of renewable electricity capacity has doubled since 2000. Particularly, the United States led the world in energy production from geothermal and biomass in 2013 [1]. There has been adoption of geothermal heat pump (GHP) systems at a fast pace. Around 85,000 GHP systems are installed each year and the total number of installation has already doubled over the past decade [2]. By use of shallow geothermal energy, GHP system provides a renewable source of energy for space cooling and heating applications. It merits the advantages such as with low carbon foot print, low maintenance requirements, environmentally friendly and widely applicable. These features make it appealing for both residential and commercial building applications.

Ground-coupled heat pump (GCHP) system is a closed loop GHP system that extracts thermal energy from the ground. It is a shallow geothermal energy technique that utilizes the relatively stable ground temperature below a certain depth. The typical GCHP system is comprised by three parts: geothermal heat exchanger (GHE), heat pump and space cooling or heating unit. Based on the spatial arrangement of GHEs, it can be classified into two major categories, i.e., vertical GCHP system and horizontal GCHP system (Fig. 1). The vertical GCHP system requires less amount of space for pipe installation, extract larger amount of thermal energy per unit length, and works with soil with little variations in the temperature and thermal properties [3]. However, installation cost for vertical GCHP is typically high, with the cost for drilling accounts for about half of the GCHP installation cost. This is typically a limiting factor for its deployment. The horizontal GCHP system requires less installation cost. It, however, requires installation under large areas and is typically affected by the variation of ground temperature and moisture. An promising alternative type of GHE is via integration with underground geostructures such as energy piles or thermoactive foundation, where the GHEs are incorporated into these geostructures (piles, walls and slabs) [4]. This multifunctional application avoids the separate drilling cost associated with the installation of traditional GCHP. There are, however, still needs to understand the influence of thermomechanical coupling on the performance of these geostructures.
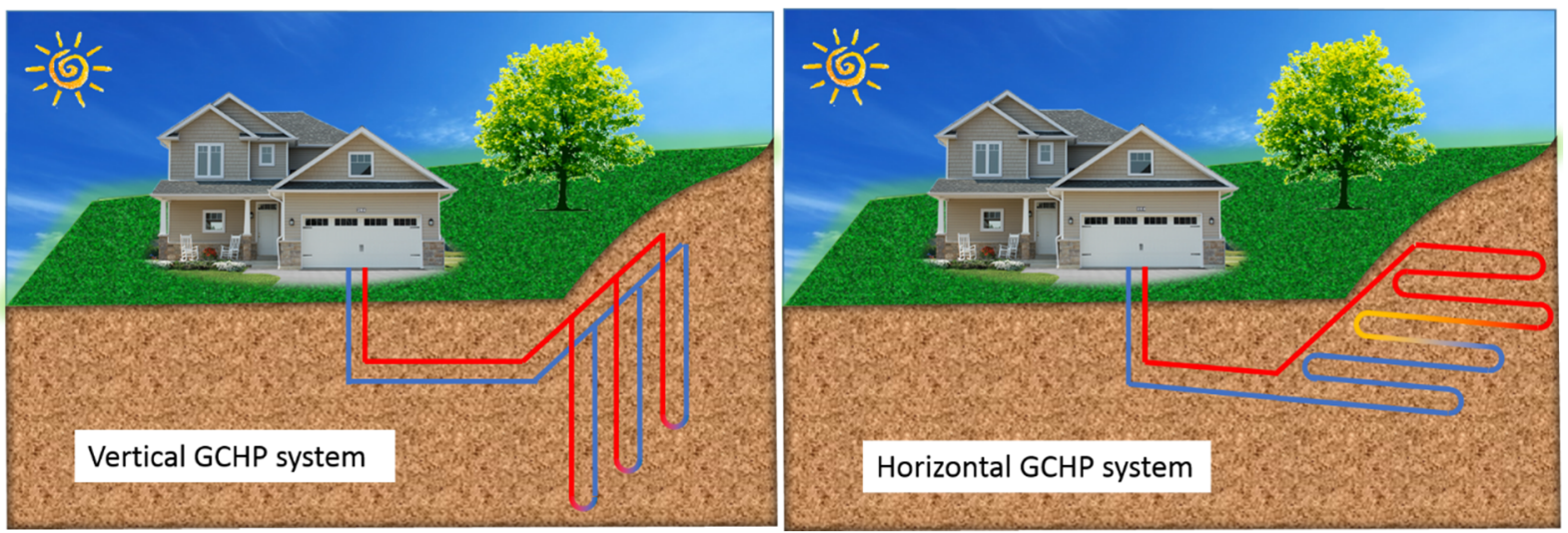

Fig. 1. Configuration of vertical and horizontal GCHP system

Fig. 2 illustrates the working principle of GCHP system, in which, the circulated fluid (water or other antifreeze fluid) inside GHE absorbs (or disperses) the heat through the U-shaped pipes (typically high-density polyethylene (HDPE) pipes). The water is then used to heat (or cool) the space. Depending upon the season, the ground can serve either as the heat sink during summer or the heat source during winter. As the GHE plays a crucial role in the 


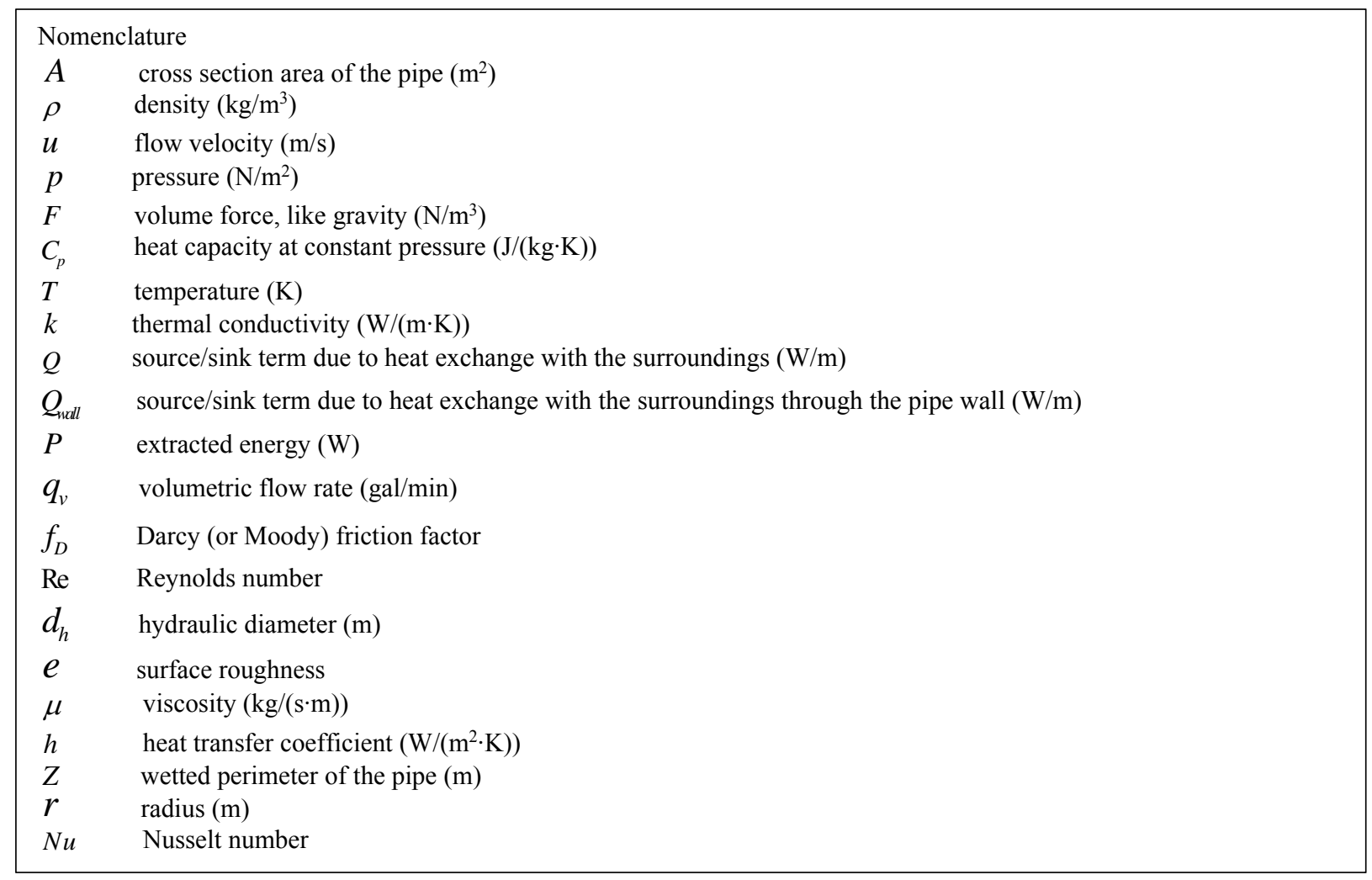

performance of the overall system, there have been tremendous efforts to develop simulation models of GHE, which could be either analytical models or numerical models, to understand the associated heat transfer process. Recently, Li et al. [5] conducted a comprehensive overview of the GHE heat transfer analytical models, and Sarbu et al. [6] summarized the most typical simulation and thermal response test (TRT) models. Koohi-Fayegh and Rosen [7] also reviewed and compared some analytical and numerical models. Although analytical model performs great privilege in both computational efficiency and accuracy [5], practically for the long-term performance evaluation, numerical model has been widely deployed to analyze short-term response as well as lone-term response. Because more parameters, like grout heat capacity, moisture migration, trainset boundary conditions, etc., could be easier involved in the numerical model than the analytical model [7].

The complexity of GHE heat transfer process normally originates from variations in the geological conditions, arrangement, geometric and materials of GHE, flow conditions, and operation modes, etc. The estimation of the key influencing parameter was carried out by both analytical models and numerical models. For example, some numerical models were established to illustrate the fact that the presence of subsurface water flow can improve geothermal energy extraction and ground thermal field recovery [8-14]. Analytically, the moving line source method was developed [15] and advanced [16-20] to investigate the influence of ground water flow. Wang et al [21] applied finite element model and the improved ring-coils analytical model on a spiral arranged GCHP system providing support the fact aforementioned. The simulation study by Choi, et al. [22] showed that the saturated soil condition contributed to $40 \%$ higher mean heat exchange rate than unsaturated soil condition. Factors such as the shank spacing, borehole depth, flow velocity, thermal properties, inlet temperature and arrangement have also been investigated. The borehole depth was found to be the most significant factor affecting the system performance [11]. Chung, et al. [23] suggested that increasing the flow velocity in heat pump unit could improve the performance of GCHP system, but there was a trade-off between thermal energy harvest and electrical energy consumption for pumping. The performance of GCHP system was also found to be enhanced by increasing pipe spacing, applying high thermal conductivity grouts, and maintaining larger temperature difference between the inlet fluid temperature and the ground [11,24]. Study via Monte Carlo technique by Arteconi, et al. [25] showed that the most important parameter in system design is the temperature of heat storage tank. Adbelaziz, et al. [26] developed a multilayer finite line source model to account for layered ground conditions. Over the past decade, many scientific efforts were devoted to explore the performance of 
GCHP system with GHE pipe arranged in spiral coil, practically for energy pile application. In addition to numerical models [14, 21, 27], the analytical models of solid cylindrical heat source model [28], spiral heat source model [29], ring-coil source model [30] and helical-line-source model [31] were proposed, which provided powerful tools for GHE optimal design. Then Leroy et al [32] advanced the spiral source model by taking axial effects into consideration yielding more reasonable and precise results. Furthermore, from system integration perspective, researches have been conducted by use of TRNSYS model to evaluate the performance of GCHP integration with building operation [26, 33-38]. The intermittent operation mode of GCHP was found to improve the overall performance of GCHP system [22, 34, 39-42]. In addition to residential and commercial building applications, other types of applications of GCHP system, such as pavement snow melting, has also been reported by researchers [43-44]. Hybrid GCHP system with slinky pattern [45-46] were also explored by both experiments and computational modelling.

These previous studies have made significant progresses in developing simulation models to understand the behaviors of GHE. For the numerical simulation, their conclusions were either based on stationary model or transient model, which are suitable for different situations (continuous operation behaviors versus short term transient responses). This paper presents a comprehensive model for the GHE, which describes the heat exchange between fluid and GHE pipes as well as the heat transfer between GHE pipe and the ground. Both transient and steady state behaviors of the GHE are analyzed. Sensitivity analyses are conducted on the major factors affecting GHE performance. The performance of GHE under continuous and intermittent operation modes is also compared, including long term cost-benefits analyses. Recommendations are provided to optimize the design and operation of the GHE.

\section{Numerical model development}

\subsection{Theoretical basis}

The theoretical framework is developed firstly to holistically describe the heat exchange between circulation fluid and GHE pipe as well as that between GHE pipe and the ground. The model is then implemented in finite element model to simulate the heat exchange process during the operation of an in-service GHE. The heat exchange process is driven by the temperature difference between the circulating fluid in the pipe and the surrounding ground (soil or rock). When the temperature of the circulating fluid is lower than the ground, heat is absorbed by the fluid from the pipe wall. The reduced temperature of the pipe wall causes a heat flux from the ground towards the GHE pipe. The physical description for this process is mathematically expressed as follows.

\section{Heat exchange between fluid and GHE pipe}

The heat exchange between the fluid and GHE pipe is described by the model for non-isothermal pipe flow (Equation (1)). Equation (1) describes the convection transfer between the fluid and the pipe wall, which includes continuity equation, momentum equation and energy conservation equation:

$$
\left\{\begin{array}{l}
\frac{\partial A \rho}{\partial t}+\nabla \cdot(A \rho u)=0 \\
\rho \frac{\partial u}{\partial t}=-\nabla p-\frac{1}{2} f_{D} \frac{\rho}{d_{h}}|u| u+F \\
\rho A C_{p} \frac{\partial T}{\partial t}+\rho A C_{p} u \cdot \nabla T=\nabla \cdot(A k \nabla T)+\frac{1}{2} f_{D} \frac{\rho A}{d_{h}}|u| u^{2}+Q_{\text {wall }}
\end{array}\right.
$$

where A stands for the cross section area, $\rho$ is the density of fluid, $u$ is the fluid velocity, $t$ is the time, $T$ is the temperature, $p$ is the fluid pressure, $f_{D}$ is the Darcy friction factor, $d_{h}$ is the hydraulic pipe diameter, $F$ is the volume force due to fluid density variation, $C_{p}$ is the heat capacity, $k$ is the thermal conductivity of fluid, $Q_{\text {wall }}$ is the heat exchange through pipe wall. Details of the equation sets are provided in the following.

Equation (1a) is the continuity equation that describe the mass conservation. 
Equation (1b) is the momentum conservation equation. In this equation, the right hand side terms represent the pressure drop caused by internal viscous shear. $f_{D}$ is a dimensionless quantity called the Darcy (or Moody) friction factor, which depends on Reynolds number (Re), and is the function of tube surface condition that is described by the surface roughness divided by the hydraulic pipe diameter $\left(e / d_{h}\right)$ [47]. Darcy friction factor is commonly described with Churchill friction model [48], i.e.,

$f_{D}=8\left[\left(\frac{8}{\mathrm{Re}}\right)^{12}+\left(C_{A}+C_{B}\right)^{-1.5}\right]^{\frac{1}{12}}$

107

where, $C_{A}=\left[-2.475 \ln \left(\left(\frac{7}{\operatorname{Re}}\right)^{0.9}+0.27\left(\frac{e}{d_{h}}\right)\right)\right]^{16}, C_{B}=\left(\frac{37530}{\operatorname{Re}}\right)^{16}, e=0.0015 \mathrm{~mm}$.

This equation is applicable for any range of Reynolds number [49]. That's to say, it is valid for laminar flow, fully developed turbulent flow as well as the transitional region.

Reynolds number Re is a dimensionless parameter defined as the ratio of inertia and viscous force [50]. For the internal flow, it is expressed as $\operatorname{Re}=\frac{\rho u d_{h}}{\mu}$.

The term $\mathrm{F}$ in Equation (1b) is the volume force that considers the density variation, which is set as zero by assuming the circulation fluid as incompressible Newtonian fluid.

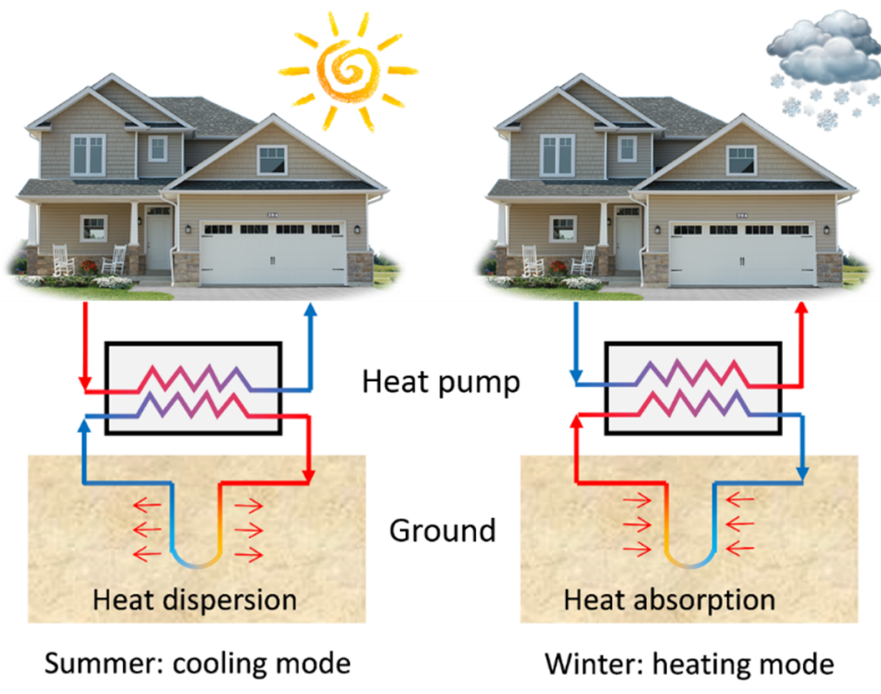

Fig. 2. Schematic of GCHP system in cooling mode and heating mode

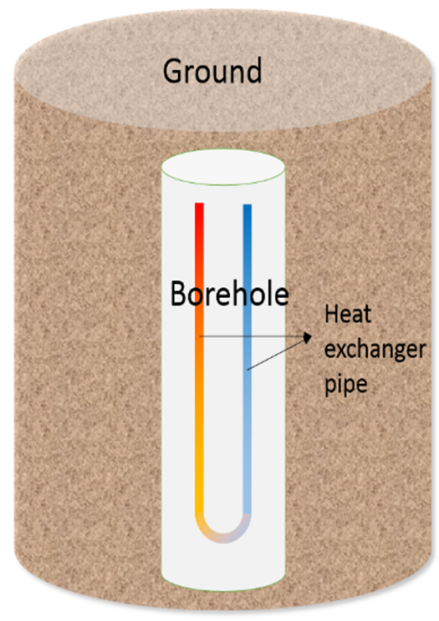

Fig. 3. Configuration of $3 D$ vertical $G H E$

Equation (1c) is the energy conservation equation, which involves conduction, convection and dissipation processes. The left hand side of this equation describes the change of thermal energy in a unit fluid cell. The first term on the right-hand side describes heat conduction. The second term on the right hand side of the equation describes heat produced by viscous shear. The term $Q_{\text {wall }}$ corresponds to the heat exchange between fluid and pipe wall, which is calculated by Newton's heat dissipation theory: 


$$
(h Z)=\frac{2 \pi}{\frac{1}{r_{i} h_{\mathrm{int}}}+\frac{1}{r_{o} h_{e x t}}+\frac{\ln \left(\frac{r_{o}}{r_{i}}\right)}{k}}
$$

where, $T$ is the fluid temperature, $T_{2, e x t}$ is the exterior temperature of the pipe wall, $h Z$ is the total thermal resistance of the pipe wall.

The influence of pipe wall on heat transfer is accounted for with an equivalent thermal resistance term that includes the contributions of the thermal resistance of the pipe and the thermal resistances of the internal and external films with convection layer, which are assumed to be in serial with each other. Therefore, the total thermal resistance of the pipe wall is described as

where $h$ is the convection coefficient. $\mathrm{Z}$ is the total thermal resistance considering those by the internal film, pipe wall and external film, $r_{i}$ and $r_{o}$ are the internal and external radius of the pipe respectively. Since the external layer is solid with no convection, $h_{e x t}$ is set as zero. For the thermal resistance of the internal fluid boundary layer, $h_{\mathrm{nnt}}$ is given by $h_{\text {int }}=N u_{\text {int }} \frac{k_{\text {water }}}{d_{h}}$, in which, $N k_{\text {int }}$ is internal Nusselt number describing the dimensionless temperature gradient at the pipe wall. In the laminar condition, the magnitude of $N_{\text {iti }}$ is 3.66 , whereas, in turbulent condition, it is calculated by:

$N u_{\text {int }}=\frac{\left(f_{D} / 8\right)(\operatorname{Re}-1000) \operatorname{Pr}}{1+1.27 \sqrt{f_{D} / 8}\left(\operatorname{Pr}^{2 / 3}-1\right)}$

in which, $\operatorname{Pr}$ is the ratio of the momentum and thermal diffusivities, i.e., $\operatorname{Pr}=\frac{C_{p} \mu}{k}$.

\section{Heat transfer in the borehole:}

$\rho C_{p} \frac{\partial T_{2}}{\partial t}=\nabla \cdot\left(k \nabla T_{2}\right)-Q_{\text {wall }}$

Equation (6) describes the heat conduction process in the borehole. It is linked with the circulation fluid via the heat exchange term $Q_{\text {wall }}$.

\section{Heat transfer with the adjacent ground:}

$\left(\rho C_{p}\right)_{e f f} \frac{\partial T_{2}}{\partial t}+\rho C_{p} u \cdot \nabla T_{2}=\nabla \cdot\left(k_{e f f} \nabla T_{2}\right)+Q$

Equation (7) describes the heat exchange process with the adjacent ground involving both thermal conduction and heat dissipation due to subsurface water flow. In this Equation (7), $u$ is the subsurface water flow velocity, it is assumed to be $40 \mathrm{~m} /$ year based on local hydrogeology conditions, it is zero above the water table. $\left(\rho \mathrm{C}_{\mathrm{p}}\right)_{\text {eff }}$ and $\mathrm{k}_{\text {eff }}$ describe the effective volumetric heat capacity and effective thermal conductivity respectively, which can be calculated as:

$\left(\rho C_{p}\right)_{e f f}=\theta_{s} \rho_{s} C_{p, s}+\left(1-\theta_{s}\right) \rho C_{p}, k_{e f f}=\theta_{s} k_{s}+\left(1-\theta_{s}\right) k$ 
where the subscript s represents the solid and $\theta_{\mathrm{s}}$ is volume fraction of solid.

Q is the heat source of sink in the ground. Since the ground in this study don't have extra heat source or sink, this term set as zero.

$T_{2, \text { ext }}$ in Equation (3) can be obtained by solving Equation (6) and (7). This term couples non-isothermal pipe flow module and heat transfer module together. The system of equations can be solved after applying appropriate boundary conditions and continuity conditions. From these the temperature distribution across the transverse section as well as along the GHE pipe can be obtained.

\subsection{Model geometry and boundary conditions}

The computational models are developed based on a prototype vertical GCHP system installed in a three-story residential house located in Cleveland, OH, United States [51]. The house is a three-story residential house with 260 $\mathrm{m}^{2}\left(2800 \mathrm{ft}^{2}\right)$ floor space. The design heating/cooling capacity of GCHP system is $11.7 \mathrm{~kW}(40,000 \mathrm{Btu} / \mathrm{hr})$. The geometric parameters and material properties of GHE used in this study are listed in Table. 1. It includes 6 vertical

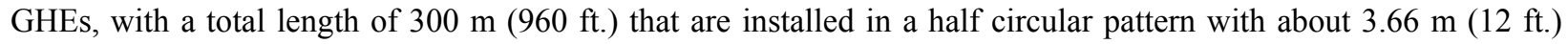
spacing. Fig. 3 illustrates the configuration of one vertical GHE, which is composed of the GHE pipes, the backfill grout and the ground.

The GCHP system was installed before the winter of 2010. A comprehensive post monitoring system was installed, which monitors the inlet and outlet temperature of GCHP, external and indoor air temperature, flow rate, electricity consumption, etc.

The numerical model includes two components, i.e., non-isothermal pipe flow and heat transfer in solid. In the non-isothermal pipe flow component, the heat exchanger pipe is HDPE pipe with an inner diameter of $21 \mathrm{~mm}$ and a wall thickness of $2 \mathrm{~mm}$. The pipe flow is simplified as one-dimensional flow, which neglects the heat exchange process in the radial direction inside the pipe. The computational domain for the adjacent ground is set to be a cylinder with the $4 \mathrm{~m}$ diameter and the diameter of the borehole is set to be $150 \mathrm{~mm}$. It is noted that the size of the computational domain with $4 \mathrm{~m}$ diameter is determined by a sensitivity study of the effects of the domain radius on the simulation results, based on considering both computational accuracy and computational time. The depth of the GHE is $50 \mathrm{~m}$ based on the prototype GHE. The geometry parameters and material properties are listed in Table 1. The ground temperature distribution is assumed to be a function of depth and time [50]:

$T(\mathrm{z}, \mathrm{t})=\mathrm{T}_{m}+T_{a} e^{-z \sqrt{\frac{\omega}{2 a_{s}}}} \cos \left[\omega\left(\mathrm{t}-\mathrm{t}_{0}\right)-\mathrm{z} \sqrt{\frac{\omega}{2 a_{s}}}\right]$

where, $\mathrm{T}_{\mathrm{m}}$ is the average ambient temperature at the ground surface, which is $11^{\circ} \mathrm{C}$ for Cleveland based on climate date records, $\mathrm{T}_{\mathrm{a}}$ is the amplitude of temperature variation at the ground surface, which is $9.1^{\circ} \mathrm{C}$ for Cleveland, $\omega$ is the angular frequency of temperature variations, which is set as $2 \pi / 365 \mathrm{~d}^{-1}, \mathrm{a}_{\mathrm{s}}$ is the solid thermal diffusivity which equals $0.8^{*} 10^{-6} \mathrm{~m}^{2} / \mathrm{s}, \mathrm{t}_{0}$ denotes to the time (in days) when the maximum surface temperature occurs, which is set as 192 days.

The ground temperature profile in different moths based on Equation (9) is shown in Fig. 4. The ground temperature approaches a constant value of $\mathrm{T}_{\mathrm{m}}$ throughout seasons for depth beyond $10 \mathrm{~m}$. This is consistent with observed in literature such as [52]. 
Table 1. GHE properties

\begin{tabular}{ll}
\hline Item & Description \\
\hline GHE type & Single U-pipe \\
Distance between two pipe legs & $70 \mathrm{~mm}$ \\
Distance between the borehole top and ground surface & $1.5 \mathrm{~m}$. \\
Pipe material & $\mathrm{HDPE}$ \\
Borehole backfilling & Bentonite \\
Ground properties & Rock or soil \\
Fluid in the pipe & Water $+10 \%$ ethyl alcohol \\
Fluid volumetric flow rate & 1.83 gallon $/ \mathrm{min}$ \\
Volume fraction of solid & 0.8 \\
Bentonite thermal conductivity & $1.7 \mathrm{~W} / \mathrm{m} / \mathrm{K}$ \\
Bentonite specific heat capacity & $1600 \mathrm{~J} / \mathrm{kg} / \mathrm{K}$ \\
Ground thermal conductivity & $2 \mathrm{~W} / \mathrm{m} / \mathrm{K}$ \\
Ground specific heat capacity & $1000 \mathrm{~J} / \mathrm{kg} / \mathrm{K}$ \\
Water thermal conductivity & $0.56 \mathrm{~W} / \mathrm{m} / \mathrm{K}$ \\
Water specific heat capacity & $4190 \mathrm{~J} / \mathrm{kg} / \mathrm{K}$ \\
Pipe wall (HDPE) thermal conductivity & $0.46 \mathrm{~W} / \mathrm{m} / \mathrm{K}$ \\
\hline
\end{tabular}

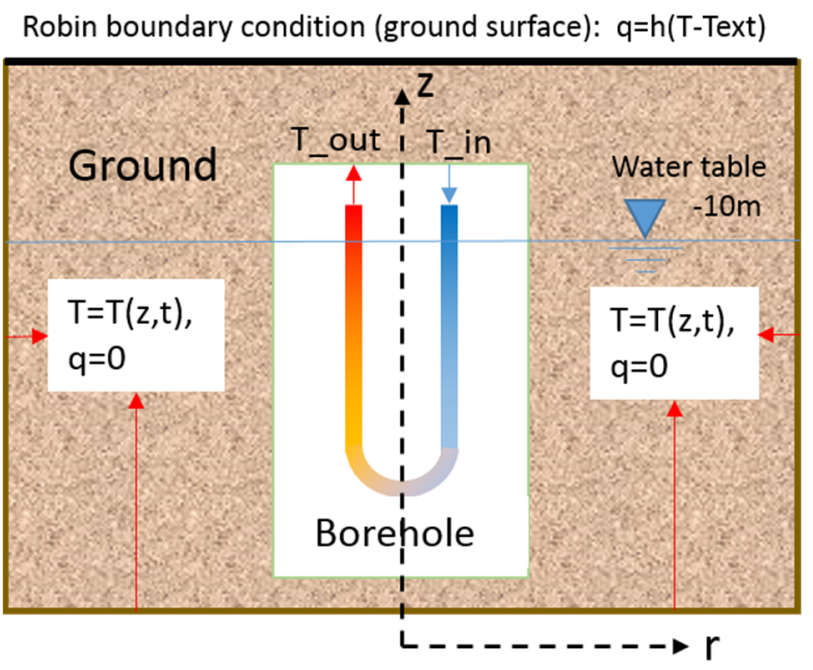

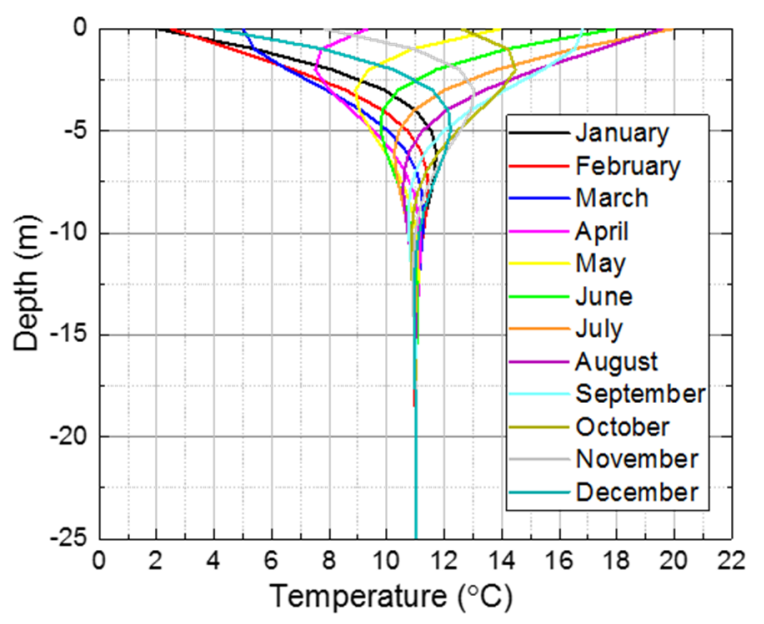

Fig. 4. The initial ground temperature profile for different moth

Fig. 5. The 3D GHE model boundary conditions

The Dirichlet boundary condition is applied on the side and bottom boundary of the computational domain (Fig. 5). The temperature boundaries are set according to the ground temperature obtained by Equation (9). In addition, the Robin boundary condition is employed at the ground surface to describe heat exchange between ground and atmosphere. The convection coefficient $h$ is assumed to be $0.53 \mathrm{~W} / \mathrm{m} / \mathrm{K}$ [53], while the surface air temperature is assigned to be $5^{\circ} \mathrm{C}$ for winter condition.

\subsection{Mesh schema optimization}

A swept mesh method was developed with triangular prismatic elements instead of tetrahedral elements, which greatly reduced the computational time without sacrificing the accuracy. With this mesh schema, triangular elements are firstly generated on the selected faces and then sweep along the axial direction either in fixed number distribution or explicit distribution. This is based on the fact that the heat transfer process in the axial direction is less significant compared with that in the radical direction. The vertical discretization near the upper and bottom layers are refined without losing the accuracy in simulation. As shown in Fig. 6, compared with free tetrahedral mesh method, the elements numbers of swept mesh method are reduced by up to 4 to 9 times for different sweeping methods, while the mesh in the lateral slice performs with sufficient quality. The difference between the results by swept mesh versus 
conventional meshing method is around 3\%, while the computational time is reduced from $317 \mathrm{~s}$ to $46 \mathrm{~s}$ (or about 6.8 times) for a stationary case. The reduction in the simulation time is crucial for simulating the time dependent process in GHE. The swept mesh method significantly improves the computational efficient while preserve the accuracy.

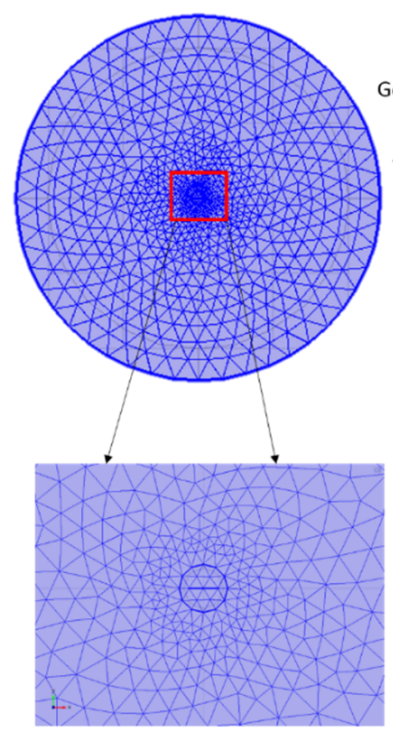

Swept mesh method Generate Surface mesh

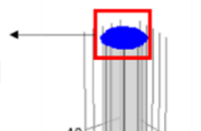

Fig. 6. Comparision of two different meshing methods

Free tetrahedral mesh method

Free

Tetrahedral
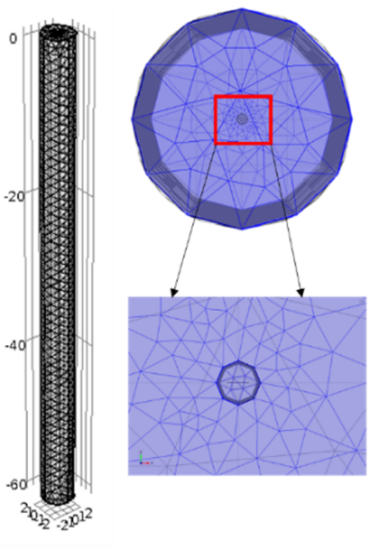

About 160,000

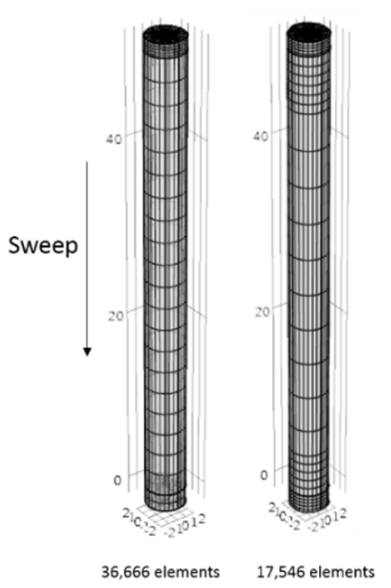


(a)

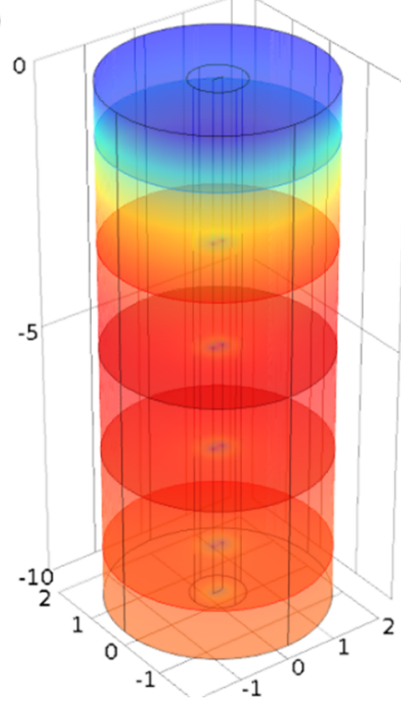

Temperature $\left({ }^{\circ} \mathrm{C}\right)$

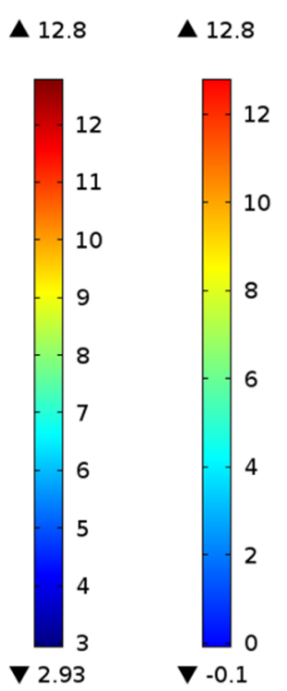

(b)

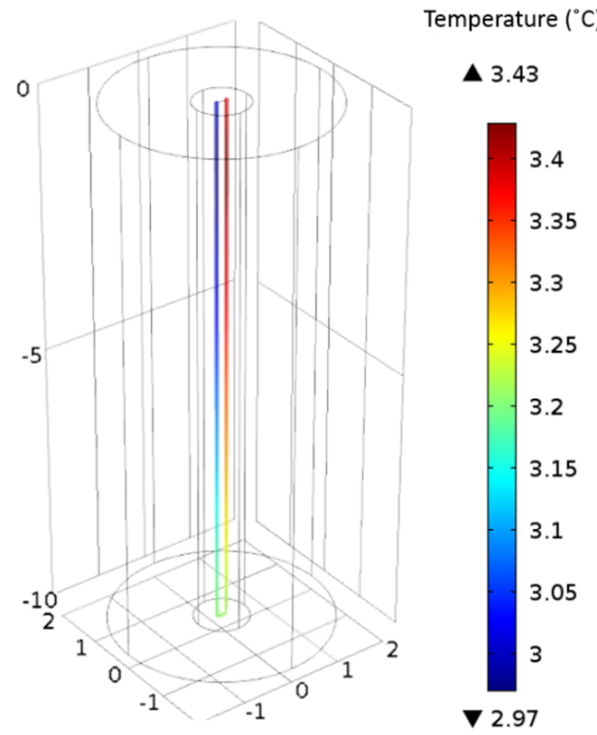

Fig. 7. Temperature profile of GHE: (a) on the radial direction; (b) along the pipe

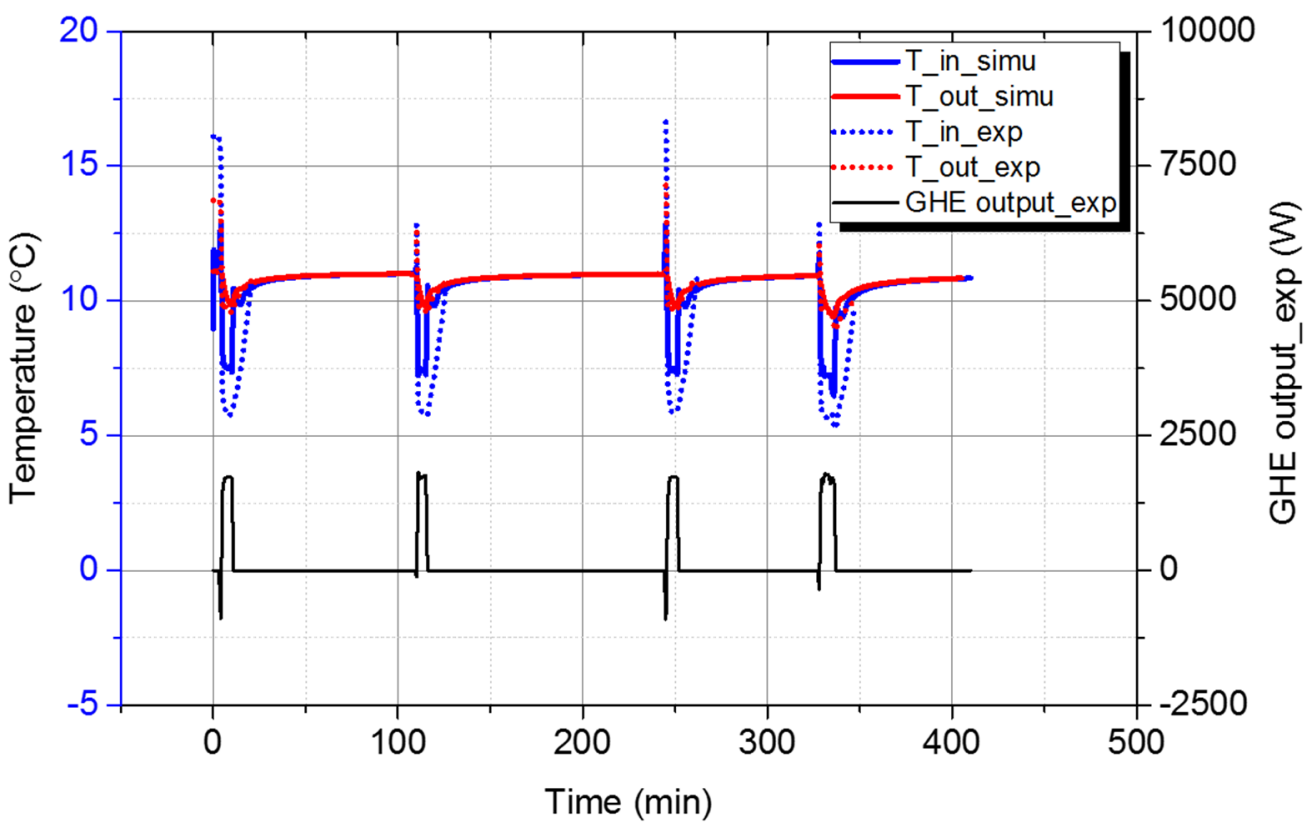

Fig. 8. Numerical solution versus experimental data

Fig. 8 compares the inlet and outlet temperatures predicted by the computational model versus field measurements when the GHE is in operation. The sharp falls (rises) are the transient responses due to the switch on/off operation of the GCHPs. The in-service GCHP system operated in an intermittent mode with feedback loop that determines the switch operation. A control system switched on/off of the GCHP system based on a tolerance level in maintaining a stable temperature in the heat exchange buffer tank. During the winter period, the GHE is activated when the tank temperature drops to below $90^{\circ} \mathrm{F}\left(32^{\circ} \mathrm{C}\right)$ and the GHE is stopped when the tank temperature reaches $100^{\circ} \mathrm{F}\left(38^{\circ} \mathrm{C}\right)$. In the process shown in Fig. 8, the GHE is deactivated when measured GHE ouput (GHE output_exp) equal 0; it is only activated otherwise. Once the heat pump is activated, the heat pump will start to absorb the heat from the circulating water in GHE, which leads to the decreases of the inlet temperature. When the heat pump is off with no water 
circulated, the inlet and outlet temperature both recover to the ground temperature. These processes lead to the the sharp rises and falls in temperature processes observed in Fig. 8.

The comparison in Fig. 8 indicates that the simulated inlet and outlet temperature processes resemble those of actual measurements. The differences are possibility due to a few factors such as the spatial non-uniformity in the underground geology conditions, which is difficult to completely capture in the simulation model. Besides, the prototype GCHP is a closed loop system whereas the simulation model is for an open loop system. These have to be addressed by conducting more detailed geology characterization and further refining the monitoring program. The comparison with measured data validated that computational model is capable of simulating the behaviors of GHE.

During the break period when there is the pump is off with no water circulated, the simulated inlet and outlet temperatures converge to the same value. It needs to point out that the on and off status discussed here only refer to GHE part of GCHP system. For the actual closed loop system in the house, the heat pump and indoor distribution system still works when GHE is off. This can lead to different temperatures at inlet and outlet.

\subsection{Sensitivity analysis}

There are many factors that can affect the heat exchange process in the GHE. Fig. 9 lists major contributing factors. Sensitivity analyses are conducted to evaluate the influence of initial temperature, flow velocity, pipe depth, subsurface water flow velocity, thermal properties of backfill and ground, and operation modes on the performance of GHE when working in the heating mode during winter. The inlet temperature to the GHE is assumed to be a fixed value, while the variations in the outlet temperature under different scenarios is used to measure the performance of

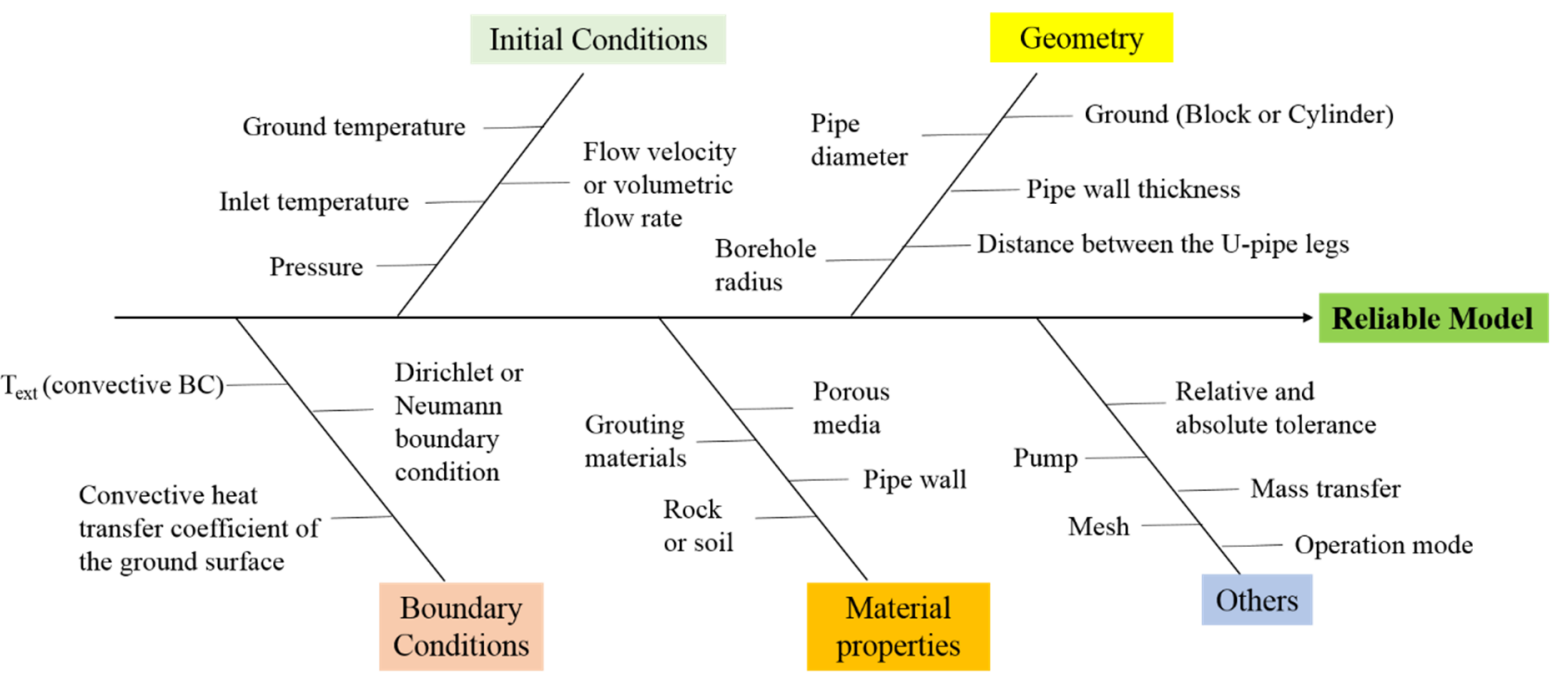

Fig. 9. Fishbone of possible influencing factors for numerical model

Table 2. The default parameters for all case studies

\begin{tabular}{ll}
\hline Item & Description \\
\hline U_shape pipe inlet temperature & $3^{\circ} \mathrm{C}$ \\
Pipe depth & $50 \mathrm{~m}$. \\
Subsurface water flow velocity & $40 \mathrm{~m} /$ year \\
Fluid volumetric flow rate & 1.83 gallon $/ \mathrm{min}$ \\
Bentonite thermal conductivity & $1.7 \mathrm{~W} / \mathrm{m} / \mathrm{K}$ \\
Bentonite specific heat capacity & $1600 \mathrm{~J} / \mathrm{kg} / \mathrm{K}$ \\
Ground thermal conductivity & $2 \mathrm{~W} / \mathrm{m} / \mathrm{K}$
\end{tabular}




\section{Initial Temperature}

Initial temperature field needs to be assigned to start the computational simulation. Fig. 10 is used to demonstrate the influence of the initial temperature at the outlet, which is conceptually related to the inlet temperature of GHE and the amount of heat extracted from the ground. For the continuous operation mode, the GHE is assumed to work continuously with no stop; while for the intermittent operation mode, the GHE is assumed in the on/off modes. Fig 10 shows that the initial temperature at the outlet only has a short influence on its trends of variations (less than 15 minutes), i.e., the outlet temperature converges to a defined temperature process that is only decided by the output temperature process of GHE and the amount of heat extracted by the GHE. This observation is true for both continuous operation and intermittent operation modes. Since the actual operation under either continuous or intermittent operation mode last much longer than 15 minutes, therefore the conclusions from the computational simulations are independent of the initial temperature conditions at the outlet.

Another aspect to point out, the results showed in Fig. 10 are all obtained by 3D transient model, which implies that the outlet temperature varies with time. In Fig. 10(a), it shows the outlet temperature keeps decreasing with time in the continuous operation mode. Under this mode, the outlet temperature continues to decrease due to the thermal built-up effects in the adjacent ground, which leads to the deterioration of GCHP system. However, for the intermittent operation mode (Fig. 10(b)), when the GCHP system stops, the outlet temperature and the adjacent ground recover to the ground temperature, which will alleviate the thermal built-up effects in the ground and help to improve the efficiency of GCHP system.
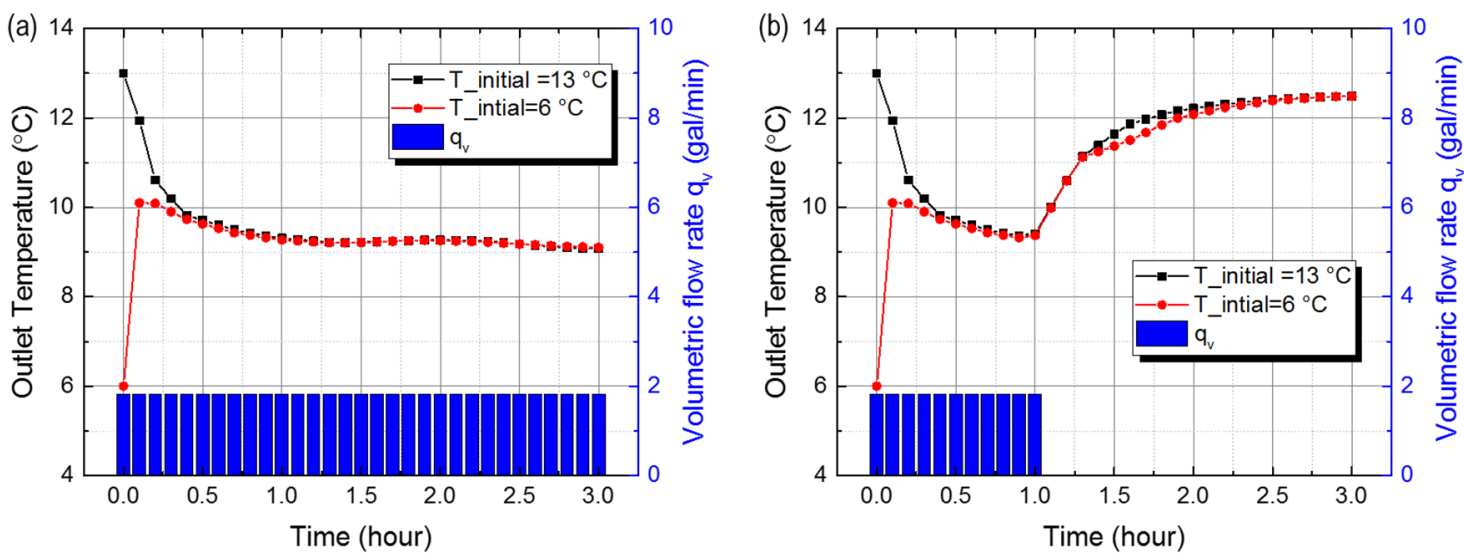

Fig. 10. Influence of initial temperature (a) GHE works in continuous operation mode (b) GHE works in intermittent mode

\section{Subsurface Water Flow}

Simulation cases are designed to simulate the effects of subsurface water flow on GHE heat extraction. The water table is set as $10 \mathrm{~m}$ below the ground surface. Ground water flow at speed of $40 \mathrm{~m} / \mathrm{year}$. Fig. 11 shows the underground temperature profiles at depths above the water table $(-8 \mathrm{~m}$ level $)$ and underground water table $(-12 \mathrm{~m})$. It shows that the presence of subsurface water flow generally increases the temperature adjacent to the heat exchange pipe. Consequently, the temperature difference between the pipe fluid and the ground is increased, which leads to larger rate of thermal energy extraction. This is further illustrated in Fig. 12, which summarizes the simulated outlet temperature at different speeds of subsurface water flow. Compared with no subsurface water flow, the outlet temperature of the GHE increases with the increasing of subsurface water flow velocity. The differential temperature between inlet and outlet increases about $44 \%$ for subsurface water flow at speed of $v=40 \mathrm{~m} /$ year compared with there is no subsurface water flow. This confirms the previous observation that the presence of subsurface water flow significantly improves the performance of GCHP system [8-21]. 

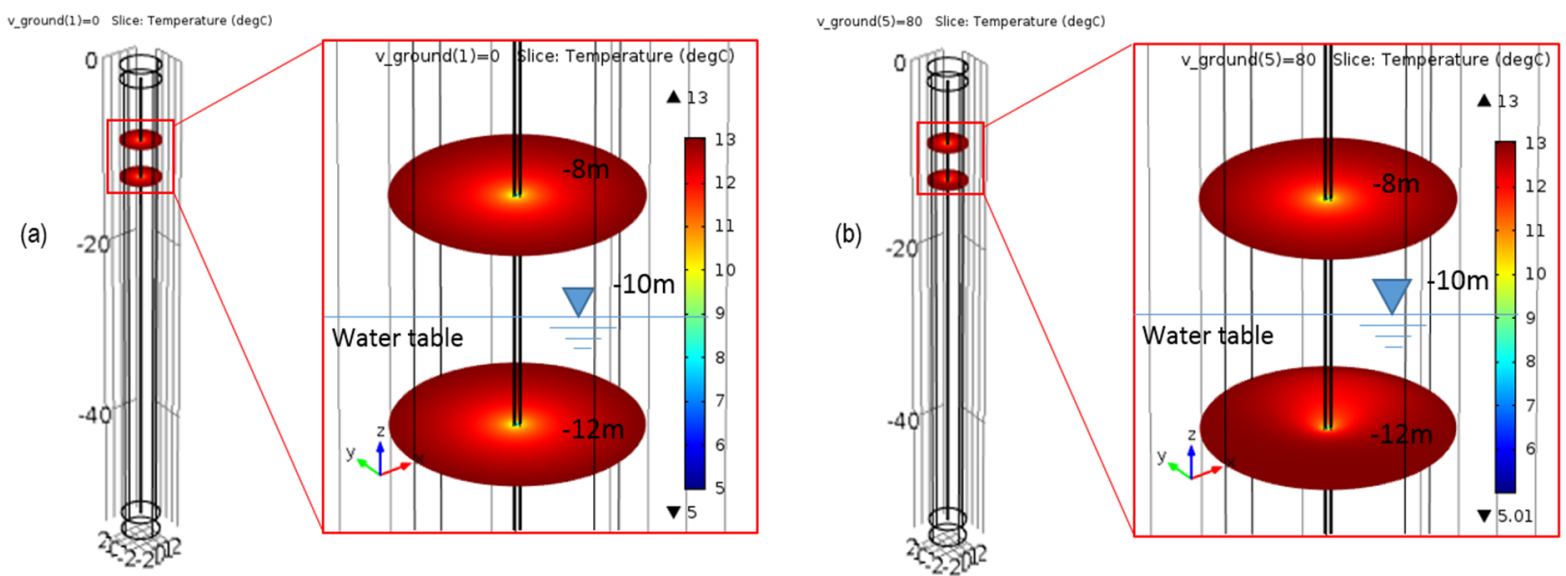

Fig. 11. Temperature profile (a) without subsurface water flow (b) with subsurface water flow

\section{Inlet Temperature}

Fig. 13 plots the influence of inlet temperature on the simulated steady state outlet temperature of the GHE operating in the continuous operation modes. The inlet temperature changes from $0^{\circ} \mathrm{C}$ to $9^{\circ} \mathrm{C}$. Simulation is conducted with 3D stationary model. It's necessary to point out that the results by $3 \mathrm{D}$ stationary model correspond to the results obtained from 3D transient model after around 10 hours' continuous operation. The application of stationary model greatly saves the computational time. As shown in Fig. 13, it can be seen that the outlet temperature increases linearly with the inlet temperature; the temperature difference between inlet and outlet, however, decreases closely linearly as the inlet temperature increases. This is consistent with the fact that the larger the temperature difference between inlet and ground temperatures, the more thermal energy can be harvested by GHEs or vice versa. The closer the inlet fluid temperature to the ground temperature, the less the amount of thermal energy extraction. The implication for GCHP operation is to set the inlet fluid temperature as high as possible in summer for the cooling period and as low as possible in winter for the heating period.

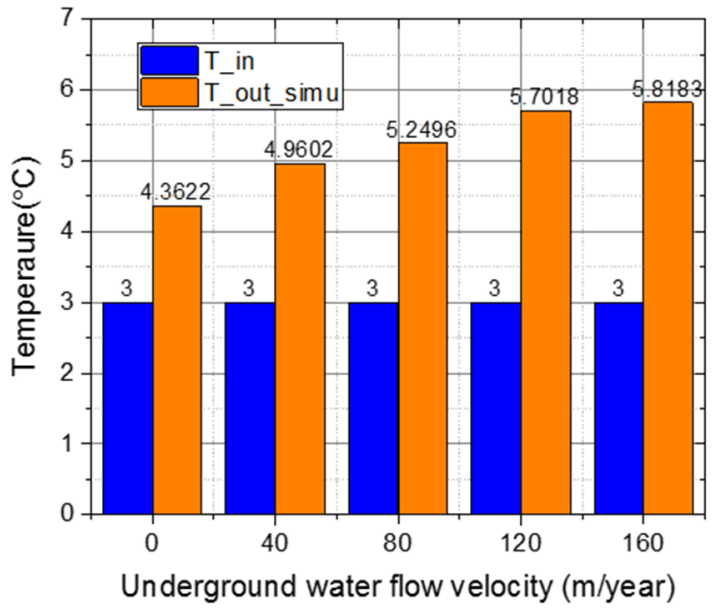

Fig. 12. Influence of subsurface water flow velocity

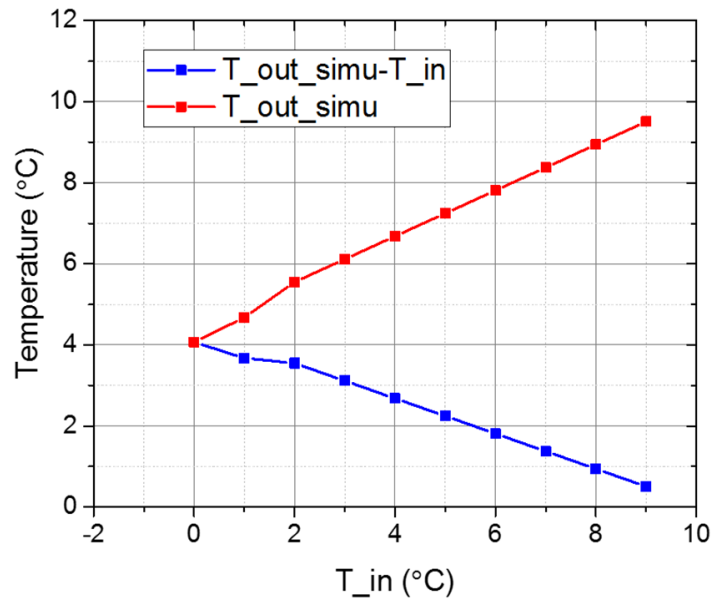

Fig. 13. Influence of the U_shape pipe inlet temperature

\section{GHE Pipe Depth and Flow Velocity}

Fig. 14 and 15 summarize the results of sensitivity analyses on the influence of GHE pipe depth $(H)$ and circulated fluid velocity (u) via stationary model and transient model respectively. Fig. 14(a) and Fig. 15(a) show that the outlet temperatures decrease with the increasing flow velocity and the decreasing GHE pipe depth. Since the outlet temperature alone cannot measure the performance of GHE operating under different length and flow velocity, the 
total extracted energy is introduced as the quantitative measure the performance, which is defined by $P=\rho C_{p} u A\left(T_{-}\right.$out $-\mathrm{T}_{-}$in $)$. The variation of total extracted energy with $\mathrm{H}$ and $\mathrm{u}$ are plotted in Fig. 14(b) and Fig. 15(b). Generally, the total extracted energy increases with the increasing flow velocity and GHE pipe depth. However, based on the results of stationary model (which describes the performance of the GHE in the steady state condition after about 10 hours' continuous operation), the extracted energy reaches a constant after the flow velocity exceeds the corresponding critical value for a certain GHE length. For example, at $\mathrm{H}=30 \mathrm{~m}$, the total extracted energy stays at about $1300 \mathrm{~W}$ for fluid velocity larger than its critical value of $0.3 \mathrm{~m} / \mathrm{s}$. Thus, the optimal fluid circulation speed is around $0.3 \mathrm{~m} / \mathrm{s}$ for GHE $30 \mathrm{~m}$ in length. Overall, for GHE in continuous operation mode, when the flow velocity is below the critical value, both flow velocity and GHE pipe depth have major influence on GHE performance; however, once the flow velocity exceeds the critical value, the GHE pipe depth performs the dominant effect on the system performance.
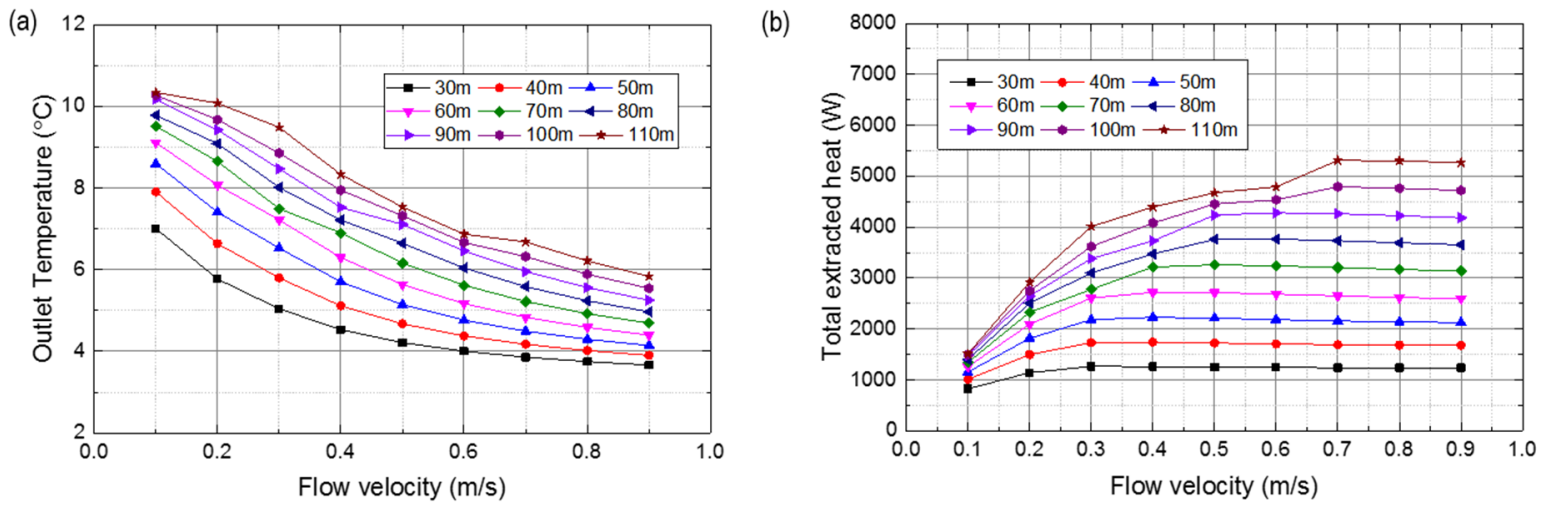

Fig. 14. Influence of fluid flow velocity and GHE pipe depth via stationary model

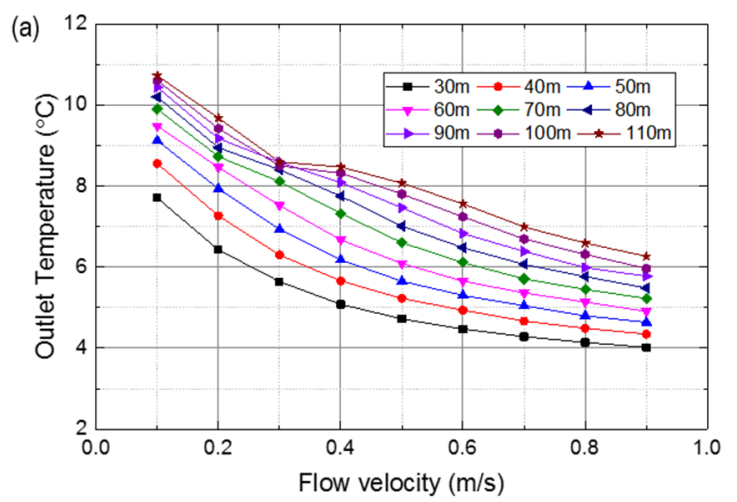

(b)

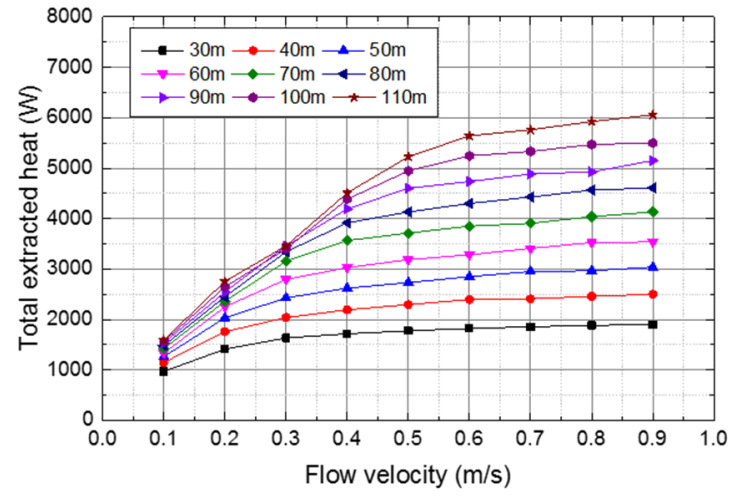

Fig. 15 Influence of fluid velocity and GHE pipe depth via transient model

\section{Thermal Properties}

Fig. 16 summarizes the influence of backfill material and ground thermal properties of the GHE under continuous operation mode. The outlet temperature is used as the indicator for the performance of GHE under the same installation depth and flow velocity. The results indicate that thermal conductivities of both the backfill grouting material and the ground have appreciable effects on the GHE performance; besides, the difference due to such influence decreases with increasing thermal conductivity. This is consistent with the general observation that higher thermal conductivity benefits energy extraction. Factors such as heat capacity only have insignificant influence on the energy extraction for continuous operation. 
(a)

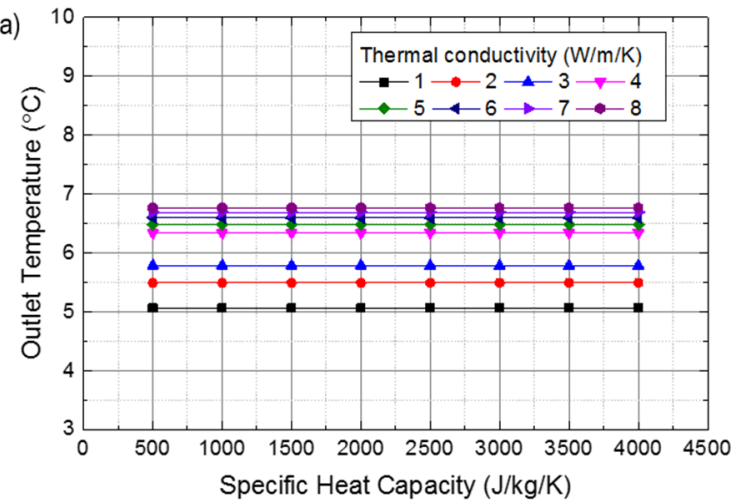

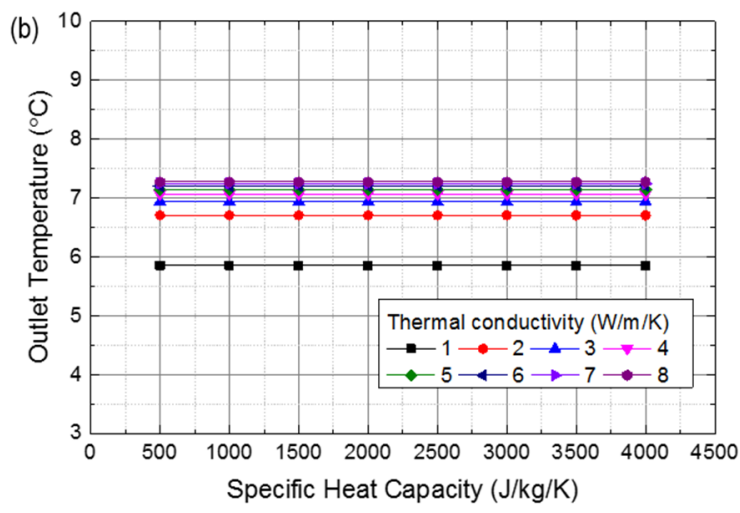

Fig. 16. Influence of (a) ground and (b) backfill material thermal properties via stationary model

The in-service GCHP systems are usually operated in intermittent mode rather than continuous mode. The stationary model is insufficient to illustrate the transient behavior of the system with different thermal properties. Therefore, the 3D transient model is also employed to investigate the influence of thermal properties on the transient behaviors of the GHE. The results are summarized in Fig. 17, with the outlet temperature after one hour of operation used as the indicator of GHE performance. The result shows both thermal conductivity and specific heat capacity of backfill grouting material and subsurface geomaterials affect the GHE performance. Besides, the effect of the thermal properties of the backfill material is much greater than that of the ground.

Comparison of Fig. 16 and Fig. 17, i.e., the sensitivity of thermal conductivity and heat capacity on the GCHP performance operating under continuous versus intermittent modes, lead to interesting observations in our opinion. Many current GHE design methods primarily focus on measuring the thermal conductivity as well as the response of the ground under steady state conditions. These include the commonly conducted thermal response tests for GHE, which measures the outlet temperature under steady state conditions. The observation from our simulation indicates that characterizing the thermal conductivity alone is insufficient. The heat capacity, particularly those of the grouting material, can have a major influence on the efficiency. As it affects the ground temperature recovery for the intermittent operation mode.

(a)

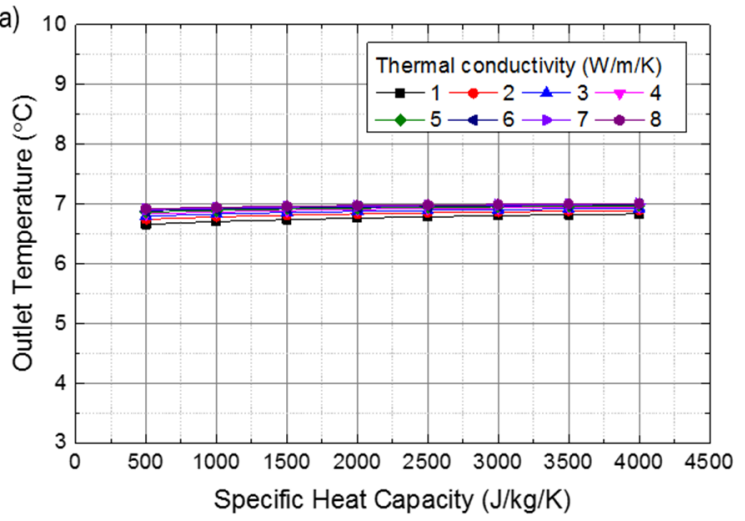

(b)

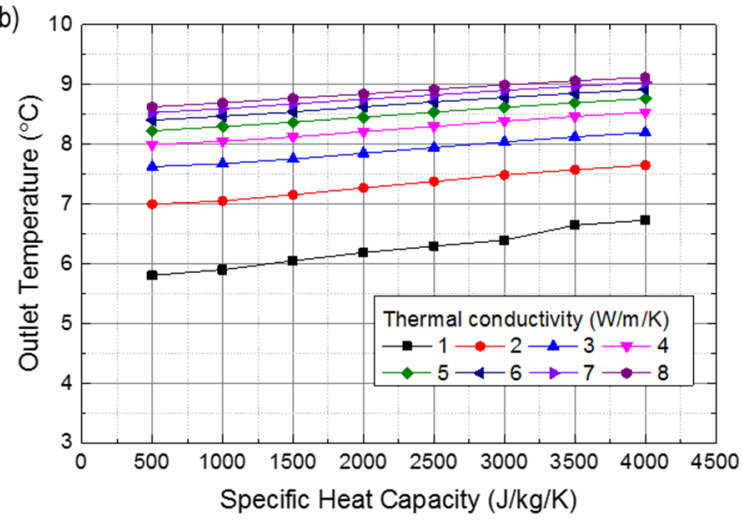

Fig. 17. Influence of (a) ground and (b) backfill material thermal properties via transient model

From practical consideration, it is difficult to change the thermal properties of ground, but there are many techniques could be applied to backfill grouting materials to achieve certain thermal properties. Efforts have been made by the industry to improve the thermal properties of backfill material, primarily focusing on the improvement of its thermal conductivity. The influence of specific heat capacity of the backfill material is typically neglected, as the design is mostly based on steady state conditions. The results of model simulation in this study indicate that although the heat capacity does not influence the geothermal heat exchanger in continuous operation mode (or under 
steady state condition), it can have a significant influence on the geothermal heat exchanger operating in the transient mode. This points to a new direction to further improve GHE performance, i.e., to optimize both the thermal conductivity and specific heat capacity of the grouting materials to maximize the performance of GHE.

\section{Continuous versus Intermittent Working Mode}

The GCHP system is usually operated in an intermittent mode based on the controlling criteria of HVAC operation. In other words, the system is switched on or off based on the heating or cooling demands of a specific building. Fig. 18 compares the predicted GHE outlet temperature process under different operation modes. In the continuous operation mode (Fig. 18(a)), the outlet temperature decreases with time continuously until it approaches a relatively steady value. While in the intermittent operation mode (Fig. 18(b)), the outlet temperature decreases during the operation period; it then recovers during the off period. For both operation modes, the extracted energy can be calculated by integration of the extracted heat:

$P_{\text {total }}=\int_{0}^{t} P(t) d t=\int_{0}^{t} \rho C_{p} \mathrm{q}_{v}\left(T_{-}\right.$out $-T_{-}$in $) d t=\rho C_{p} \int_{0}^{t} \mathrm{q}_{v}\left(T_{-}\right.$out $-T_{-}$in $) d t$

As an example comparison, GHE operated for 50000 seconds (13.89 hours) was divided into 5 working period, each with 10,000 seconds (2.78 hours). The extracted energy for each working period is determined with Equation (10) and is plotted in Fig. 19(a). The results show that while the continuous operation mode extracts more energy than intermittent operation mode over the whole working period, the efficiency in energy extraction (defined as the extracted energy divided by the operation period) is higher in the intermittent operation mode than continuous operation mode. This results are consistent with the observation that the intermittent operation mode helps improve GHE performance by allowing ground temperature recovery, which also helps to mitigate the shift of ground baseline temperature. Documented case studies have shown that the shift of ground baseline temperature is a limiting factor for the performance of densely installed GCHPs.

Based on monitored energy data [50], it is assumed that the average electrical energy consumption rate is about $0.4 \mathrm{~kJ} / \mathrm{s}$ (400 watts) for the circulation pump and heat pump, the total electrical energy consumption during each 10,000 seconds ( 2.78 hours) working period is $4000 \mathrm{~kJ}$ (Fig. 19(b)). The COP is calculated as the ratio of extracted energy and consumed electrical energy, which is shown in Fig. 19. Although the continuous operation mode extracts more energy compared with intermittent mode $(\mathrm{P}>\mathrm{P})$, the intermittent operation mode actually features higher $\mathrm{COP}$, due to reduction of electrical energy consumption for pump operation. This indicates the intermittent operation mode is more energy efficient. For the simulated case in this case study, around $8000 \mathrm{~kJ}(2.22 \mathrm{kWh})$ total electrical energy is saved by use of intermittent operation mode, which leads to around $\$ 65$ annual cost reduction (assume the unit price of electricity in Cleveland is around $\$ 0.12 / \mathrm{kWh}$ ) over the heating season (between Oct. $1^{\text {st }}$ and May. $1^{\text {st }}$ ).
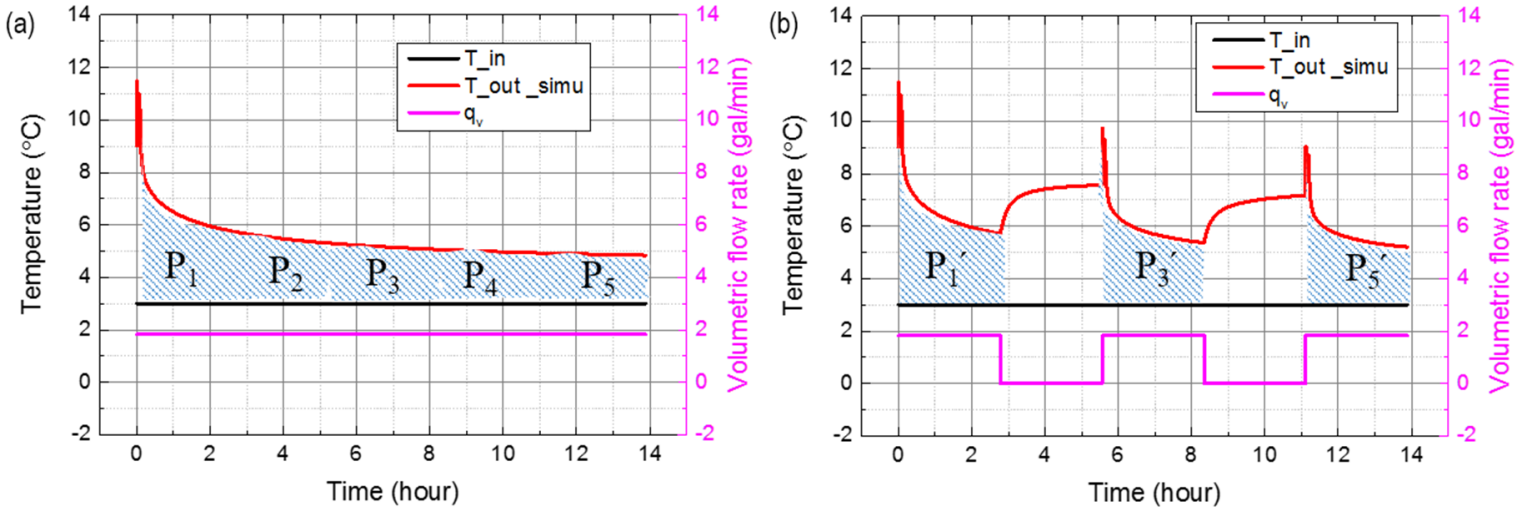
(a)

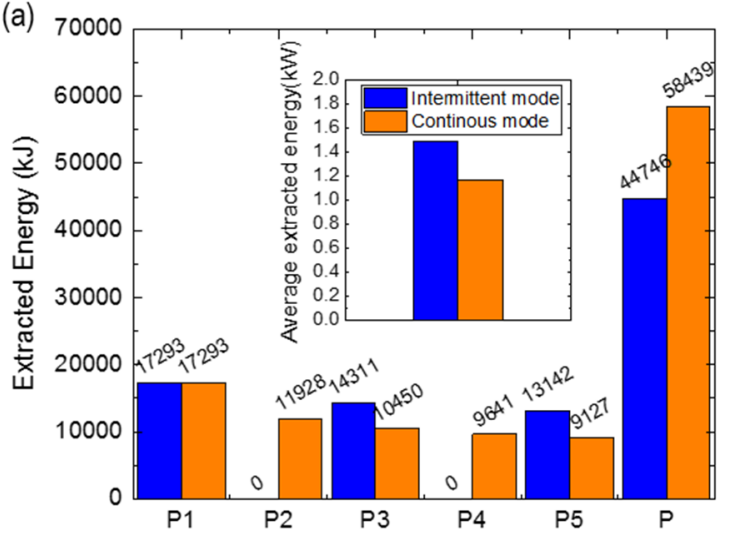

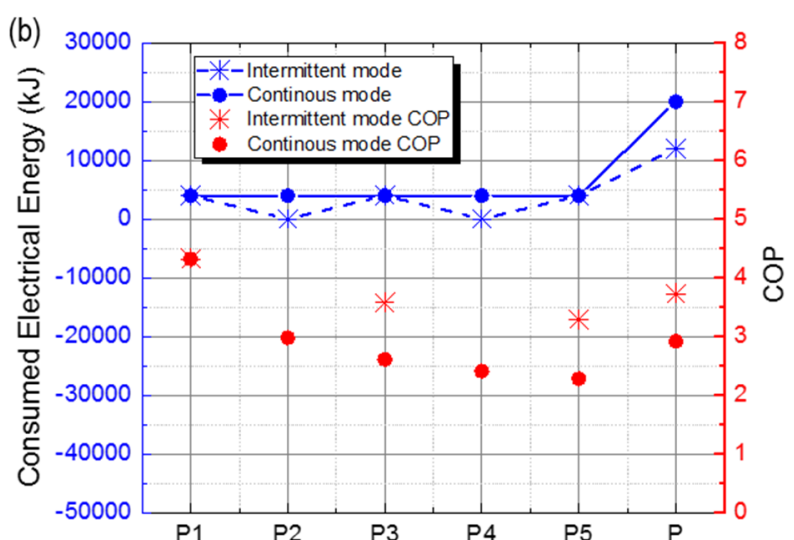

Fig. 19. (a) Extracted energy and (b) Consumed electrical energy and corresponding COP on different working period

The shift of ground baseline temperature due to thermal built-up will negatively affect the efficiency of GHEs. This is something that need to be addressed from design and operation perspectives. The intermittent operation mode allows the ground to recover its original temperature and achieves higher efficiency. Compared with long-term continuous operation mode, under the intermittent operation mode, the ground could get a chance to recover its temperature to the original level after a certain time of operation. This mitigates the thermal built-up effects in the adjacent ground. According to Fig. 19, intermittent operation mode performs advantages in both efficiency (COP) and energy consumption, primarily due to ground temperature recovery.

\section{Conclusions}

This paper conducts sensitivity analyses of geological, design, and operational factors on the performance of GHE. It presents the development and implementation of a holistic 3D FEM model for GHE, which simulates the stationary (or steady state) and transient behaviors of the GHE. The simulation models were firstly validated by comparing the model simulation results with field experimental data collected from an in-service GHE. This verified the reliability of the simulation model. On the basis of this model, a series of sensitivity analyses are conducted on the influence of a number of factors on GHE performance, including initial ground temperature, GHE pipe installation length, operation parameters (circulation fluid flow velocity), inlet temperature, and subsurface water flow velocity, and thermal properties of grouting materials, etc. From these key factors affecting the design and operation of GHE are identified.

In the geological design aspect, the thermal conductivity of the ground material plays a very important role on the GHE performance operating in the continuous operation mode, while its specific heat capacity exerts no appreciable influence. However, for intermittent operation mode, both thermal conductivity and specific heat capacity of the ground, particularly the grouting materials, affect the ground thermal energy extraction. This observation provides a new direction for improving GHE performance, i.e., optimizing both the thermal conductivity and specific heat capacity of backfill materials. The presence of subsurface water flow can significantly increase the amount of thermal energy extracted by GHE.

In the operation aspect, for a certain design length of GHE, the GHE performance improves with higher circulation fluid flow velocity until beyond a critical velocity. Therefore, there are room to optimize the circulation fluid velocity in GHE to achieve the maximum performance. Comparison of the performance of GHE under different operational strategies, i.e., continuous operation mode and intermittent mode, shows that for a particular GHE, intermittent operation mode has advantages in reducing the operation cost as well as improving the efficiency in thermal energy extraction. Intermittent operation mode allows underground thermal recovery and achieves higher COP. 
Results from the sensitivity study shed light on potential ways to improve the performance of GHE from both design and operation aspects. The numerical model presented in the study provides a useful tool to evaluate the GHE performance. There are still many local geology characteristics affecting GHE performance that need further analyses, i.e., the thermal induced water migration in the unsaturated zone, the regional geology conditions, and the interferences between a group of GHEs. These will need to be further studied.

\section{Acknowledgement}

This research is partially supported by the National Science Foundation and China Scholarship Council.

\section{Reference}

[1] A. M. Tang, J.-M. Pereira, G. Hassen, and N. Yavari, "Behavior of Heat-Exchanger Piles from Physical Modeling," in Energy Geostructures, ed: John Wiley \& Sons, Inc., 2013, pp. 79-97.

[2] R. Al-Khoury, P. G. Bonnier, and R. B. J. Brinkgreve, "Efficient finite element formulation for geothermal heating systems. Part I: steady state," International Journal for Numerical Methods in Engineering, vol. 63, pp. 988-1013, 2005.

[3] ASHRAE. American Society of Heating, Refrigerating and Air-Conditioning Engineers., "2007 ASHRAE HandbookHVAC Applications," p. Ch32, 2007.

[4] L. Laloui, M. Nuth, and L. Vulliet, "Experimental and numerical investigations of the behaviour of a heat exchanger pile," International Journal for Numerical and Analytical Methods in Geomechanics, vol. 30, pp. 763-781, 2006.

[5] M. Li and A. C. K. Lai, "Review of analytical models for heat transfer by vertical ground heat exchangers (GHEs): A perspective of time and space scales," Applied Energy, vol. 151, pp. 178-191, 8// 2015.

[6] I. Sarbu and C. Sebarchievici, "General review of ground-source heat pump systems for heating and cooling of buildings," Energy \&amp; Buildings, vol. 70, pp. 441-454, 2014.

[7] S. Koohi-Fayegh and M. A. Rosen, "A Review of the Modelling of Thermally Interacting Multiple Boreholes," Sustainability, vol. 5, pp. 2519-2536, 6// 2013.

[8] G.-H. Go, S.-R. Lee, S. Yoon, and H.-b. Kang, "Design of spiral coil PHC energy pile considering effective borehole thermal resistance and groundwater advection effects," Applied Energy, vol. 125, pp. 165-178, 7/15/ 2014.

[9] H. J. G. Diersch, D. Bauer, W. Heidemann, x000Fc, W. haak, Sch, et al., "Finite element modeling of borehole heat exchanger systems," Computers and Geosciences, vol. 37, pp. 1136-1147, 2011.

[10] A. Di Donna and L. Laloui, "Soil Response under Thermomechanical Conditions Imposed by Energy Geostructures," in Energy Geostructures, ed: John Wiley \& Sons, Inc., 2013, pp. 3-21.

[11] S. E. Dehkordi and R. A. Schincariol, "Effect of thermal-hydrogeological and borehole heat exchanger properties on performance and impact of vertical closed-loop geothermal heat pump systems," Hydrogeology Journal, vol. 22, pp. 189203, 2014.

[12] A. Casasso and R. Sethi, "Efficiency of closed loop geothermal heat pumps: A sensitivity analysis," Renewable Energy, vol. 62 , pp. 737-746, 2014.

[13] S. Al-Zyoud, W. Rühaak, and I. Sass, "Dynamic numerical modeling of the usage of groundwater for cooling in north east Jordan - A geothermal case study," Renewable Energy, vol. 62, pp. 63-72, 2// 2014.

[14] V. Wagner, P. Bayer, M. Kübert, and P. Blum, "Numerical sensitivity study of thermal response tests," Renewable Energy, vol. 41, pp. 245-253, 5// 2012.

[15] L. R. Ingersoll, O. J. Zobel and A. C. Ingersoll.. Heat conduction with engineering, geological, and other applications. Revised ed. Madison: The University of Wisconsin Press; 1954.

[16] N. Diao, Q. Li, and Z. Fang, "Heat transfer in ground heat exchangers with groundwater advection," International Journal of Thermal Sciences, vol. 43, pp. 1203-1211, 12// 2004.

[17] N. Molina-Giraldo, P. Bayer, and P. Blum, "Evaluating the influence of thermal dispersion on temperature plumes from geothermal systems using analytical solutions," International Journal of Thermal Sciences, vol. 50, pp. 1223-1231, 7// 2011.

[18] N. Molina-Giraldo, P. Blum, K. Zhu, P. Bayer, and Z. Fang, "A moving finite line source model to simulate borehole heat exchangers with groundwater advection," International Journal of Thermal Sciences, vol. 50, pp. 2506-2513, 12// 2011.

[19] A. Capozza, M. De Carli, and A. Zarrella, "Investigations on the influence of aquifers on the ground temperature in ground-source heat pump operation," Applied Energy, vol. 107, pp. 350-363, 7// 2013.

[20] M. Tye-Gingras and L. Gosselin, "Generic ground response functions for ground exchangers in the presence of groundwater flow," Renewable Energy, vol. 72, pp. 354-366, 12// 2014.

[21] D. Wang, L. Lu, W. Zhang, and P. Cui, "Numerical and analytical analysis of groundwater influence on the pile geothermal heat exchanger with cast-in spiral coils," Applied Energy, 2015. 
[22] J. C. Choi, S. R. Lee, and D. S. Lee, "Numerical simulation of vertical ground heat exchangers: Intermittent operation in unsaturated soil conditions," Computers and Geotechnics, vol. 38, pp. 949-958, 2011.

[23] J. T. Chung and J. M. Choi, "Design and performance study of the ground-coupled heat pump system with an operating parameter," Renewable Energy, vol. 42, pp. 118-124, 6// 2012.

[24] L. Jun, Z. Xu, G. Jun, and Y. Jie, "Evaluation of heat exchange rate of GHE in geothermal heat pump systems," Renewable Energy, vol. 34, pp. 2898-2904, 12// 2009.

[25] A. Arteconi, C. Brandoni, G. Rossi, and F. Polonara, "Experimental evaluation and dynamic simulation of a ground coupled heat pump for a commercial building," International Journal of Energy Research, vol. 37, pp. 1971-1980, 2013.

[26] S. L. Abdelaziz, T. Y. Ozudogru, C. G. Olgun, and J. R. Martin, "Multilayer finite line source model for vertical heat exchangers," Geothermics, vol. 51, pp. 406-416, 2014.

[27] A. Zarrella, A. Capozza, and M. De Carli, "Analysis of short helical and double U-tube borehole heat exchangers: A simulation-based comparison," Applied Energy, vol. 112, pp. 358-370, 2013.

[28] Y. Man, H. Yang, N. Diao, J. Liu, and Z. Fang, "A new model and analytical solutions for borehole and pile ground heat exchangers," International Journal of Heat and Mass Transfer, vol. 53, pp. 2593-2601, 6// 2010.

[29] Y. Man, H. Yang, N. Diao, P. Cui, L. Lu, and Z. Fang, "Development of spiral heat source model for novel pile ground heat exchangers," HVAC\&R Research, vol. 17, pp. 1075-1088, 2011/12/01 2011.

[30] P. Cui, X. Li, Y. Man, and Z. Fang, "Heat transfer analysis of pile geothermal heat exchangers with spiral coils," Applied Energy, vol. 88, pp. 4113-4119, 11// 2011.

[31] M. Li and A. C. K. Lai, "Heat-source solutions to heat conduction in anisotropic media with application to pile and borehole ground heat exchangers," Applied Energy, vol. 96, pp. 451-458, 8// 2012.

[32] A. Leroy and M. Bernier, "Development of a novel spiral coil ground heat exchanger model considering axial effects," Applied Thermal Engineering, vol. 84, pp. 409-419, 6/5/ 2015.

[33] B. Morrone, G. Coppola, and V. Raucci, "Energy and economic savings using geothermal heat pumps in different climates," Energy Conversion and Management, vol. 88, pp. 189-198, 12// 2014.

[34] F. Dupray, T. Mimouni, and L. Laloui, "Alternative Uses of Heat-Exchanger Geostructures," in Energy Geostructures, ed: John Wiley \& Sons, Inc., 2013, pp. 119-138.

[35] R. Chargui, H. Sammouda, and A. Farhat, "Geothermal heat pump in heating mode: Modeling and simulation on TRNSYS," International Journal of Refrigeration, vol. 35, pp. 1824-1832, 11// 2012.

[36] H. J. G. Diersch, D. Bauer, W. Heidemann, x000Fc, W. haak, Sch, et al., "Finite element modeling of borehole heat exchanger systems," Computers and Geosciences, vol. 37, pp. 1122-1135, 2011.

[37] A. Buonomano, F. Calise, A. Palombo, and M. Vicidomini, "Energy and economic analysis of geothermal-solar trigeneration systems: A case study for a hotel building in Ischia," Applied Energy, vol. 138, pp. 224-241, 1/15/ 2015.

[38] C. Montagud, J. M. Corberán, and F. Ruiz-Calvo, "Experimental and modeling analysis of a ground source heat pump system," Applied Energy, vol. 109, pp. 328-336, 9// 2013.

[39] S. You, X. Cheng, H. Guo, and Z. Yao, "In-situ experimental study of heat exchange capacity of CFG pile geothermal exchangers," Energy and Buildings, vol. 79, pp. 23-31, 2014.

[40] M. E. Suryatriyastuti, H. Mroueh, and S. Burlon, "Numerical Analysis of the Bearing Capacity of Thermoactive Piles Under Cyclic Axial Loading," in Energy Geostructures, ed: John Wiley \& Sons, Inc., 2013, pp. 139-155.

[41] Jalaluddin and A. Miyara, "Thermal performance investigation of several types of vertical ground heat exchangers with different operation mode," Applied Thermal Engineering, vol. 33-34, pp. 167-174, 2// 2012.

[42] Y. Shang, M. Dong, and S. Li, "Intermittent experimental study of a vertical ground source heat pump system," Applied Energy, vol. 136, pp. 628-635, 12/31/ 2014.

[43] A. Balbay and M. Esen, "Experimental investigation of using ground source heat pump system for snow melting on pavements and bridge decks," Scientific Research and Essays, vol. 5, pp. 3955-3966, 12// 2010.

[44] A. Balbay and M. Esen, "Temperature distributions in pavement and bridge slabs heated by using vertical ground-source heat pump systems," Acta Scientiarum. Technology, vol. 35, pp. 677-685, 2013.

[45] M. Esen and T. Yuksel, "Experimental evaluation of using various renewable energy sources for heating a greenhouse," Energy and Buildings, vol. 65, pp. 340-351, 10// 2013.

[46] H. Esen, M. Esen, and O. Ozsolak, "Modelling and experimental performance analysis of solar-assisted ground source heat pump system," Journal of Experimental \& Theoretical Artificial Intelligence, pp. 1-17, 2015.

[47] G. A. Akrouch, M. Sanchez, and J.-L. Briaud, "Energy Geostructures in Cooling-Dominated Climates," in Energy Geostructures, ed: John Wiley \& Sons, Inc., 2013, pp. 175-191.

[48] C. G. Olgun and G. A. Bowers, "Ground-Source Bridge Deck De-icing Systems Using Energy Foundations," in Energy Geostructures, ed: John Wiley \& Sons, Inc., 2013, pp. 211-225.

[49] M. E. Suryatriyastuti, H. Mroueh, and S. Burlon, "Impact of Transient Heat Diffusion of a Thermoactive Pile on the Surrounding Soil," in Energy Geostructures, ed: John Wiley \& Sons, Inc., 2013, pp. 193-209.

[50] C. Doughty and A. Nir, Tsang, Chin-Fu, "Seasonal thermal energy storage in unsaturated soils: Model development and field validation," 1991.

[51] C. Han and X. Yu, "Performance of a residential ground source heat pump system in sedimentary rock formation," Applied Energy, vol. 164, pp. 89-98, 2/15/2016.

[52] A. Zarrella, A. Capozza, and M. De Carli, "Performance analysis of short helical borehole heat exchangers via integrated modelling of a borefield and a heat pump: A case study," Applied Thermal Engineering, vol. 61, pp. 36-47, 2013. 
[53] Z. Du and Y. Zhang, "Numerical research on the effect of Thermal Disturbance on Soil Temperature Fields around wells of Vertically Buried Single-U-Tube Ground Heat Exchanger," Journal of Convergence Information Technology, vol. 7, pp. 383-391, 2012. 